\title{
WAWASAN Jurnal Ilmiah Agama dan Sosial Budaya
}
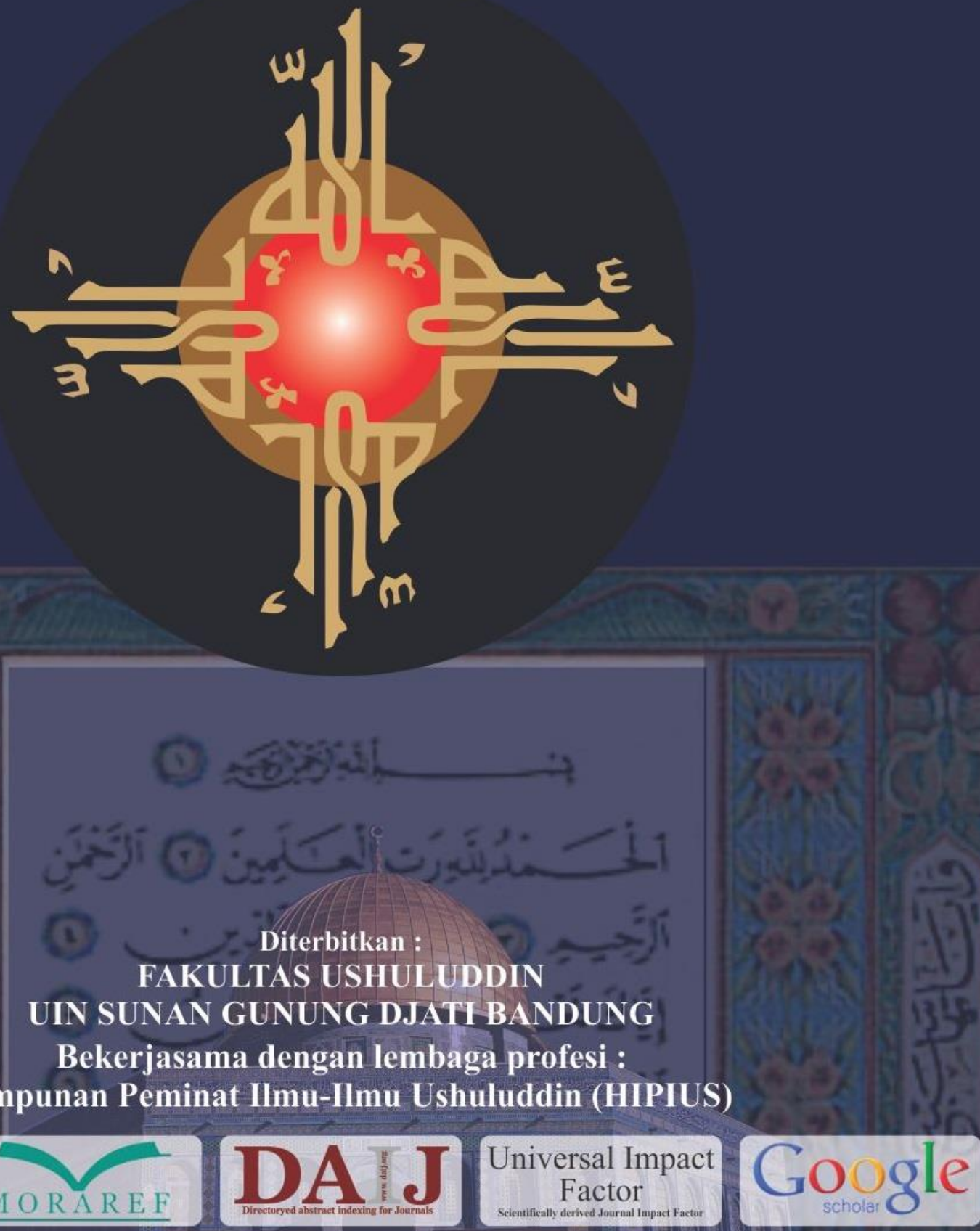

WAWASAN

Vol. 1

No. 1

Hlm. 1-126

Bandung, Januari 2016 


\section{WAWASAN}

\section{JURNAL ILMIAH AGAMA DAN SOSIAL BUDAYA UIN SUNAN GUNUNG DJATI BANDUNG}

PENANGGUNG JAWAB:

Dekan Fakultas Ushuluddin UIN Sunan Gunung Djati Bandung

\section{KETUA DEWAN PENYUNTING} Husnul Qodim

\author{
ANGGOTA DEWAN PENYUNTING \\ Ali Masrur \\ Dodo Widarda \\ Irma Riyani \\ Iu Rusliana \\ Saleh Rahmana
}

\section{DEWAN PENYUNTING AHLI}

Abdul Mustaqim

(Universitas Islam Negeri Sunan Kalijaga Yogyakarta, Indonesia) Abdul Syukur

(Universitas Islam Negeri Sunan Gunung Djati Bandung, Indonesia) Asman Taeali

(Prince of Songkla University, Pattani, Thailand) Etin Anwar

(Hobart and William Smith Colleges, USA) Florian Pohl

(Emory University, Atlanta, USA) Hasse $\mathbf{J}$

(Universitas Muhammadiyah Yogyakarta, Indonesia) Islah Gusmian

(Sekolah Tinggi Agama Islam Negeri Surakarta, Indonesia) M. Nur Kholis Setiawan

(Universitas Islam Negeri Sunan Kalijaga Yogyakarta, Indonesia) Muhammad Ali Nurdin

(Universitas Islam Negeri Sunan Gunung Djati Bandung, Indonesia) Nur Rofiah

(Universitas Islam Negeri Syarif Hidayatullah Jakarta, Indonesia) Suhadi Kholil

(Universitas Gadjah Mada Yogyakarta, Indonesia) Yasir Alimi

(Universitas Negeri Semarang, Indonesia)

$$
\begin{aligned}
& \text { LAYOUT: } \\
& \text { Busro }
\end{aligned}
$$

Busro

\section{ALAMAT REDAKSI:}

Lantai 2 Gedung Fakultas Ushuluddin

JI. Raya A.H. Nasution No. 105 Cibiru Kota Bandung, 40614 Telpon/Fax: 022-7812063

Handphone: $081336100400 / 08986143832$

E-mail: jur.wawasan@gmail.com/ wawasan@uinsgd.ac.id

\section{ALAMAT E-JURNAL:}

http://journal.uinsgd.ac.id/index.php/jw

\section{PENERBIT:}

Fakultas Ushuluddin UIN Sunan Gunung Djati Bandung bekerjasama dengan Lembaga Profesi Himpunan Peminat IImu-IImu Ushuluddin (HIPIUS)
DAFTAR ISI

Kiki Muhamad Hakiki

ISLAM DAN DEMOKRASI:PANDANGAN INTELEKTUAL MUSLIM DAN PENERAPANNYA DI INDONESIA

$$
1-17
$$

Hendar Riyadi

KOEKSISTENSI DAMAI DALAM MASYARAKAT MUSLIM MODERNIS $18-33$

Khaerul Umam

NGAJI RASA DALAM PANDANGAN KOMUNITAS DAYAK INDRAMAYU

$34-45$

Afriadi Putra

PEMIKIRAN HADIS KH. M. HASYIM ASY'ARI DAN KONTRIBUSINYA TERHADAP KAJIAN HADIS DI INDONESIA

$$
46-55
$$

Rosihon Anwar, Dadang Darmawan dan Cucu Setiawan KAJIAN KITAB TAFSIR DALAM JARINGAN PESANTREN

$$
\text { DI JAWA BARAT }
$$

$56-69$

\section{Sihabuddin Afroni}

MAKNA GHULUWDALAM ISLAM: BENIH EKSTREMISME BERAGAMA

$$
70-85
$$

Syahrullah Iskandar

STUDI ALQURAN DAN INTEGRASI KEILMUAN: STUDI KASUS UIN SUNAN GUNUNG DJATI BANDUNG

$$
86-93
$$

Ali Mursyid

BENARKAH YUSUF DAN ZULAIKHA MENIKAH? ANALISA RIWAYAT ISRA'ILIYYATT DALAM KITAB TAFSIR

$$
94-115
$$

Muhammad Solahudin

METODOLOGI DAN KARAKTERISTIK PENAFSIRAN DALAM TAF $\overline{\text { IIR }}$ $A L-K A S H S H \bar{A} F$ $116-126$ 